\title{
Mean Post Operative Pain Score in Midline Laparotomy Incisions Made using Scalpel VS Monopolar Diathermy
}

\author{
Usaid Farooque, Raheel Ahmed, Dileep Kumar
}

\begin{abstract}
OBJECTIVE: To compare mean post-operative pain score in midline laparotomy incisions made using scalpel versus mono-polar diathermy.

METHODOLOGY: Present study was Randomized Controlled trial conducted at Department of Surgery, Dr. Ruth Katherina M. Pfau Civil Hospital Karachi from July 2016 to June 2017. A total 80 patients were randomly divided in two equal groups. Group A patients underwent exploratory laparotomy with scalpel with disposable blade while Group B with monopolardiathermy in cutting mode. Postoperatively pain score was measured using Visual Analogue Scale.

RESULTS: Mean age was $31.45 \pm 9.69$. Mean pain score on post operative day 1 was $8.60 \pm 0.92$ in group $A$ (Scalpel) and $5.98 \pm 0.26$ in group $B$ (Diathermy). Mean pain score on day 2 and 3 was $7.25 \pm 0.8$ vs $3.80 \pm 0.9$ and $5.5 \pm 0.6$ vs $2.7 \pm 0.8$ in group $A$ and $B$ respectively. $P$-value was found to less than 0.001 and therefore greatly significant.

CONCLUSION: The findings of this study show that incision made by diathermy is safe and effective in terms of post-operative pain as compared to scalpel incision.
\end{abstract}

KEY WORDS: Diathermy, Emergency Midline Laparotomy, Visual analogue scale.

This article may be cited as: Farooque U, Ahmed R, Kumar D. Mean Post Operative Pain Score in Midline Laparotomy Incisions Made using Scalpel VS Monopolar Diathermy. J Liaquat Uni Med Health Sci. 2019;18(02):99-103. doi: 10.22442/jlumhs.191820609

\section{INTRODUCTION}

Emergency abdominal surgeries are mostly performed with the adequate length of incision which can ease the surgeons with the wide operative view and does not constrain using multiple surgical instruments. ${ }^{1}$ Midline incision is the mostly preferred route by the surgeons as it permits rapid access to look all the intraperitoneal visceras and enter retroperitoneal structures if required ${ }^{2-4}$. Postsurgical pain is the most commonly observed complaint of the patients undergoing abdominal incision which involves parietal peritoneum ${ }^{5-6}$. Conventionally skin incisions have been made with the help of scalpel for long time, but these incisions result potential tissue damage with blood loss and immediate post-operative pain which leads to more morbidity.

Effective post-operative pain management is of utmost importance to improve patient outcome, sense of wellbeing, and satisfaction from medical care and for early mobilization as well ${ }^{7-9}$. However, a constant research and innovative technology made it possible in identifying other methods of skin incision, and modern electrosurgical instruments have achieved great concern in this regard ${ }^{10}$. Since its invention by Bovie, electrosurgery is now used mostly for underlying dissection and hemostasis ${ }^{11,12}$.
In diathermy, the electrical current is converted to a high frequency alternating current with the range of $0.2-3 \mathrm{MHz}$ which passes through the body and excite tissue molecules and generates energy ${ }^{13}$. This thermal effect of diathermy results in partial or complete damage of sensory nerve fibers and subsequently impairing of transmission of nerve impulses ${ }^{11}$. In addition to decreased early postoperative wound pain the use of diathermy has been associated with safety and possible more benefit when applied for skin incision ${ }^{4,5,11,12,15}$.

The postoperative pain is one of the most common unresolved health care complaints with profound effects on morbidity and quality of life with slowed recovery and increased hospital stay and health care $\operatorname{costs}^{25}$. The present study so far has focused specifically on postoperative pain as a primary outcome. Moreover, in view of the contradictory results of different studies, our study was conducted in the population with particular focus on post-operative pain in midline skin incisions in emergency laparotomies with important concern to evaluate the better method over the others which would cause less post-operative pain to the patient, important factor of post-operative morbidity and thus beneficial to the recovery of patient. 


\section{METHODOLOGY}

This single blind randomized controlled trial was carried out at department of surgery, Dr. Ruth Katherina M. Pfau Civil Hospital Karachi, from July 2016 to June 2017. Informed consent was taken including purpose of the research, methods involved in making skin incision using either scalpel or diathermy and the use of Visual Analogue Scale $(V A S)^{26}$ was explained to the patients before proceeding for the surgery. Patients of both genders between 18-60 years of age presenting in emergency department were assessed clinically with tense and tender abdomen on examination consistent with the diagnosis of acute abdomen or having free gas under diaphragm on erect or lateral decubitus chest x-ray undergoing exploratory laparotomy were included. Patients presenting in emergency department with poly trauma or firearm injury requiring additional incisions or procedures and patients requiring re-exploration were excluded.

Sample size of 80 was calculated by using OpenEpi sample size calculator, taking mean \pm S.D of post-operative pain score in scalpel versus diathermy group for making midline laparotomy incisions ${ }^{4}$ of $3.10 \pm 1.04$ versus $1.22 \pm 0.18$, confidence interval $95 \%$, power of test $80 \%$ and level of significance $5 \%$. Randomization was done using sealed envelopes with allocations to either method determined just prior to surgery. Scalpel group was labeled as group $A$ and diathermy group was labeled as group $B$. Patients were blinded about the method of making incision but consent was taken for both methods. Patients were stabilized in emergency department upon arrival. I.V. line was maintained, inj ketorolac $30 \mathrm{mg}$ and prophylactic antibiotic (inj ceftriaxone $1 \mathrm{~g}+\mathrm{inj}$ metronidazole $500 \mathrm{mg}$ ) were given and baseline investigations were done. Patients were then taken to

TABLE I: DETAILS OF OUTCOME MEASURE emergency operation theatre.

All procedures were done in general anesthesia. In scalpel group, midline laparotomy incision was made by scalpel with single use blade whereas in diathermy group, midline incision was made by monopolar diathermy in cutting mode. In both methods, hemostasis was secured with monopolar diathermy in coagulation mode. Exploratory laparotomy was done and at the end, abdomen was closed by mass closure with prolene 1" and skin was also closed with prolene $2 / 0$ interrupted mattress sutures. Acute postoperatively pain management in both groups of patients was done with inj ketorolac $30 \mathrm{mg}$. Patients were inquired about the pain and score was measured with the simple use of Visual Analogue Scale (from 0 to 10) on the mornings of day 1,2 and 3 postoperatively. Assessment was done individually on each postoperative day. Mean and standard deviation of all 3 days was calculated separately.

The data analysis was performed using the SPSS version 20.0. Student's t-test was applied for comparing post-operative pain scores in both groups taking $P \leq 0.05$ as significant.

\section{RESULTS}

In this study 80 patients were randomly divided by using envelop method into two equal groups as $A$ (Scalpal) and B (Diathermy) group. Mean age in years was $31.45 \pm 9.691$.Theere were $28(70 \%)$ and 25 $(62.5 \%)$ males and $12(30 \%)$ and $15(37.5 \%)$ females in group $A$ and $B$ respectively. In comparison of postoperative score pain score in both groups Mean \pm SD of day 1 in group (A and $B$ ) was $(8.60 \pm 0.928 \mathrm{v} / \mathrm{s}$ $5.98 \pm 0.660)$, day $2(7.25 \pm 0.899 \mathrm{v} / \mathrm{s} 3.80 \pm 0.966$ and day 3 was $(5.50 \pm 0.679 \mathrm{v} / \mathrm{s} 2.73 \pm 0.877)$ and $P$ value found to be greatly significant i.e. $(P<0.001)$. The outcome measures are detailed in Table $\mathrm{I}$.

\begin{tabular}{|c|c|c|c|c|c|c|}
\hline \multicolumn{7}{|c|}{ COMPARISON OF POSTOPERATIVE SCORES IN BOTH GROUP } \\
\hline $\begin{array}{l}\text { Post operative } \\
\text { scores }\end{array}$ & Group & $\mathbf{n}$ & Mean & $\begin{array}{c}\text { Std } \\
\text { Deviation }\end{array}$ & $95 \%$ C. I & P-value \\
\hline \multirow{2}{*}{ Day 1} & A & 40 & 8.60 & .928 & \multirow{2}{*}{$2.267-2.983$} & \multirow{2}{*}{0.0001} \\
\hline & $\mathrm{B}$ & 40 & 5.98 & .660 & & \\
\hline \multirow{2}{*}{ Day 2} & A & 40 & 7.25 & .899 & \multirow{2}{*}{$3.035-3.865$} & \multirow{2}{*}{0.0001} \\
\hline & $\mathrm{B}$ & 40 & 3.80 & .966 & & \\
\hline \multirow{2}{*}{ Day 3} & A & 40 & 5.50 & .679 & \multirow{2}{*}{$2.426-3.124$} & \multirow{2}{*}{0.0001} \\
\hline & $B$ & 40 & 2.73 & .877 & & \\
\hline
\end{tabular}

Applied Independent Sample t-test, $P \leq 0.05$ considered significant 


\section{DISCUSSION}

Historically stainless steel scalpel is frequently used for making skin incisions. The scalpel use can cause sharp injuries to health care professionals and more blood loss and postoperative operative site pain. Later on alternate forms of skin incisions were proposed including laser and cavitron electronic surgical aspirators and electrocautery. Electrocautery which is more economical and readily available in all operating rooms have been less favored for making skin incision because of the misconception of tissue damage or burning leading to postoperative pain, impaired wound healing or infection and hypertrophic scaring. However such dogmas are rejected and safety of electrocautery has now been well established and its use should not be precluded. Modern electrocautery devices involve the passage of high frequency of electric current which generates temperature of $1000^{\circ} \mathrm{Cat}$ targeted tissues so rapidly that the heat generated evaporates as steams rather than spread to remote structures ${ }^{16}$. This explains the results with less frequent complications like keloid formation, infection or subsequent healing with less scarring and better cosmesis ${ }^{16}$.

Several randomized clinical studies have been carried out which have proven the safety and efficacy of cautery in subcutaneous and muscle layer but its use in making skin incision is still controversial. Few studies have proven cautery as the safe and most effective as compared to scalpel in term of blood loss, time taken for making incision, early post-operative pain and analgesic requirement, cosmetic effects and wound infection $1,6,9,12,13,17-19$. The earlier concept of devitalisation within well hydrated tissues with the use electrosurgery was negated when this technique was experimented in reconstructive and cosmetic faciomaxillary surgery, paediatric surgery, rhitidoplasty and blepheroplasty by Peterson, Mann and Klippel, Kamer and Tabin respectively with different other studies which proved minimum scarring and excellent cosmetic results of diathermy over scalpel use $\mathrm{e}^{20-23}$.

In the present study similar and consistent results to other research studies were found including short incision time, less blood loss and particularly low early postoperative pain and decreased analgesic requirement when incisions was made with electrocautry ${ }^{1,4,13}$. The results of our study were also consistent with study done by Chalya PL $2013^{4}$ which showed statistically significant mean pain scores of $3.92 \pm 1.24,3.10 \pm 1.04$ and $2.40 \pm 0.20$ on postoperative days 1,2 and 3 respectively in scalpel group and scores of $2.42 \pm 0.40,1.22+0.18$ and $1.01 \pm 0.11$ in the diathermy group $(p=0.001,0.011$ and 0.021$)$ respectively. ${ }^{4}$

Similarly, another study done by Aird LN $2015^{13}$ gives mean scores of 3.13,2.69 and 2.34 in scalpel group and scores of $1.68,1.89$ and 2.48 in diathermy group on postoperative days 1,2 and 3 respectively $(p=0.018,0.211$ and 0.817 ; statistically significant on day 1 only. Meta-analysis done by Arid LN $2012^{14}$ also concluded that diathermy result significantly reduced postoperative wound pain in patients. However, another meta-analysis done by Ly J $2012^{15}$ states contradictory results with no difference in pain score on $1^{\text {st }}$ post operative day (mean difference 0.89 ; $\mathrm{P}=0.05$ ) between diathermy and scalpel incisions. Telfer JR $1993^{24}$ confirmed similar result to our study that patients which underwent emergency midline laparotomy by making skin incision with diathermy had significantly less pain and blood loss as compared to patients in scalpel was used for the same reason.

In the present study we have carefully selected inclusion and exclusion criteria, consecutive sampling along with strongest study design (RCT) and scientific and systematic calculation of sample size has strengthened our study. We also performed stratification of the analysis to control for confounders and effect modifiers. The use of objective definitions for predictor and outcome variable also minimized the source of bias in our study. There were limitations to our study. First, since it was impossible to blind the investigator or surgeon to the device being applied, this study was not a double-blind trial and the potential for bias might exist and affect the results as a confounding factor. However limited outcomes selected in our study affects the worth of our study.

\section{CONCLUSION}

Post-operative pain management has been a source of contention and challenge for the health care providers. In emergency situations demanding immediate abdominal surgery incision made by diathermy is associated with less postoperative pain and therefore reduced analgesic requirement so this should be the preferred to make incision than scalpel.

Ethical permission: Ref No. CPSP/REU/SGR-2014183-6675 Dated 21-12-2017

Conflict of interest: There was no any conflict of interest.

Funding: There was no any funding agency. 


\section{REFERENCES}

1. Farquharson M, Moran B. Surgical access to the abdomen and surgery of the abdominal wall. In Farquharson's Textbook of operative general surgery. New York: Edward Arnold; 2005; 199215.

2. Halm JA, Lip H, Schmitz PI, Jeekel J. Incisional hernia after upper abdominal surgery: a randomized controlled trial of midline versus transverse abdominal incision. Hernia. 2009; 13 (3): 275-80. doi: 10.1007/s10029-008-0469-7.

3. El-Khadrawy OH, Moussa G, Mansour O, Hashish MS. Prophylactic prosthetic reinforcement of midline abdominal incision in high risk patients. Hernia. 2009; 13(3): 267-74. doi: 10.1007/s10029009-0484-3.

4. Chalya PL, Mchembe MD, Mabula JB, Gilyoma $\mathrm{JM}$. Diathermy versus scalpel incision in elective midline laparotomy: A prospective randomized controlled clinical study. East Cent Afr J Surg. 2013; 18(1): 71-7.

5. Damani SR, Haider S, Shah SH. Scalpel versus diathermy for midline abdominal incisions. J Surg Pak(Int). 2014; 19(1): 18-21

6. Jayakumar $D$, Janarthanan $C$, Aziz A, Ahmed-Nusrath A. Transversus abdominis plane block. Trends Curr Anesth Crit Care. 2011; 1(3): 128-34. 10.1016/j.tacc.2011.01.014

7. Mrunalini P, Raju NV, Nath VN, Saheb SM. Efficacy of transverses abdominis plane block in patients undergoing emergency laparotomies. Anesth Essays Res. 2014; 8(3): 377-82. doi: 10.4103/0259-1162.143153.

8. Leaper DJ. Basic surgical skills and anastomosis. In: Russell RC, Williams NS, Bulstrode CJ, eds. Bailey and Love's Short Practice of Surgery. 24th ed. London: Arnold; 2004; 95-106.

9. Talpur AA, Khaskheli AB, Kella N, Jamal A. Randomized clinical Trial on Diathermy and Scalpel Incisions in Elective General Surgery. Iran Red Crescent Med J. 2015; 17(2): e14078. doi: 10.5812/ircmj.14078.

10. Ayandipo OO, Afuwape OO, Irabor D, Oluwatosin $\mathrm{OM}$, Odigie V. Diathermy versus scalpel incision in a heterogeneous cohort of general surgery patients in a Nigerian Teaching Hospital. Niger J Surg. 2015; 21(1): 43-47. doi: 10.4103/11176806.153193.

11. Shamim M. Diathermy vs. scalpel skin incisions in general surgery: pouble-blind, randomized, clinical trial. World J Surg. 2009; 33(8): 1594-99. doi: 10.1007/s00268-009-0064-9.

12. Ozgun $H$, Tuncyurek $P$, Boylu $S$, Erpek $H$, Yenisey $\mathrm{C}$, Kose $\mathrm{H}$, et al. The right method of midline laparotomy: what is the best choice for wound healing? Acta Chir Belg. 2007; 107(6): 682-6.

13. Aird LN, Bristol SG, Phang PT, Raval MJ, Brown CJ. Randomized double-blind trial comparing the cosmetic outcome of cutting diathermy versus scalpel for skin incision. Br J Surg. 2015 Apr; 102 (5):489-94. doi: 10.1002/bjs.9751.

14. Aird LN, Brown CJ. Systemic review and meta-analysis of electrocautery versus scalpel for surgical skin incisions. Am J Surg. 2012; 204(2): 216-221. doi: 10.1016/j.amjsurg.2011.09.032.

15. Ly J, Mittal A, Windsor J. Systemic review and meta-analysis of cutting diathermy versus scalpel for skin incision. Br J Surg. 2012; 99(5): 613-20. doi: 10.1002/bjs.8708.

16. Prakash LD, Balaji N, Kumar SS, Kate V. Comparison of electrocautery incision with scalpel incision in midline abdominal surgery - a double blind randomized controlled trial. Int J Surg. 2015; 19: 78-82. doi:10.1016/j.ijsu. 2015.04.085.

17. Johnson CD, Serpell JW. Wound infection after abdominal incision with scalpel or diathermy. $\mathrm{Br} \mathrm{J}$ Surg. 1990; 77(6): 626-8.

18. Cruse PJ, Ford R. The epidemiology of wound infection: a 10-year prospective study of 62,939 wounds. Surg Clin North Am. 1980; 60(1): 27-40.

19. Kearns SR, Connolly EM, McNally S, McNamara DA, Deasy J. Randomized clinical trial of diathermy versus scalpel incision in elective midline laparotomy. Br J Surg 2001; 88(1): 41-4.

20. Peterson A. The use of electrosurgery in reconstructive and cosmetic maxillofacial surgery. Dent Clin North Am. 1982; 26(4): 799-823.

21. Mann W, Klippel $\mathrm{CH}$. Electrosurgical skin incisions. J Pediatr Surg. 1977: 12(5): 725-6. doi:10.1016/0022-3468(77)90402-X

22. Kamer FM, Cohen $A$. High frequency needle dissection rhitidectomy. Laryngoscope. 1985; 95(9 Pt 1): 1118-20.

23. Tobin HA. Electrosurgical blepharoplasty: A technique that questions conventional concepts of fat compartmentalization. Ann Plast Surg 1985; 14 (1): 59-63.

24. Telfer JR, Canning G, Galloway DJ. Comparative study of abdominal incision techniques. Br J Surg. 1993; 80(2): 233-5. 
25. Gan TJ. Poorly controlled postoperative pain: prevalence, consequences, and prevention. J Pain Res. 2017; 10: 2287-98. doi: 10.2147/ JPR.S144066.

26. Delgado DA, Lambert BS, Boutris N, McCulloch $P$, Robbins $A$, Moreno $M$, et al. Validation of
Digital Visual Analog Scale Pain Scoring With a Traditional Paper-based Visual Analog Scale in Adults. J Am Acad Orthop Surg Glob Res Rev. 2018; 2(3): e088. doi: 10.5435/JAAOSGlobal-D$17-00088$

AUTHOR AFFILIATION:
Dr. Usaid Farooque
Department of Surgery
Dow University of Health Sciences/Civil Hospital
Karachi, Sindh-Pakistan.
Dr. Raheel Ahmed (Corresponding Author)
Department of Surgery
Dow University of Health Sciences/Civil Hospital
Karachi, Sindh-Pakistan.
Email: draheelahmed@gmail.com
Dr. Dileep Kumar
Department of Surgery
Dow University of Health Sciences/Civil Hospital
Karachi, Sindh-Pakistan.

